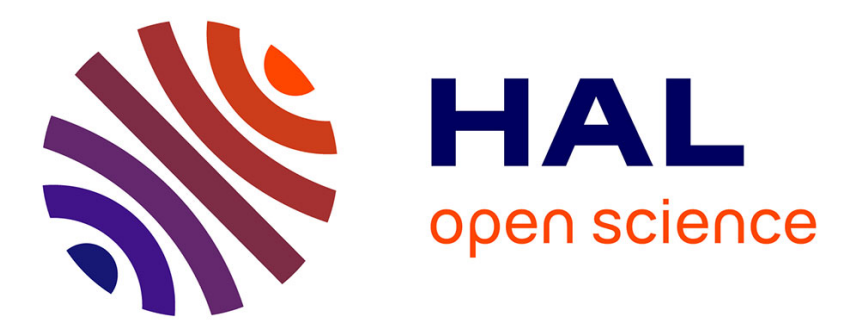

\title{
Evolutionary rate and genetic load in an emblematic Mediterranean tree following an ancient and prolonged population collapse
}

Juan Jaramillo-correa, Francesca Bagnoli, Delphine Grivet, Bruno Fady, Filippos Aravanopoulos, Giovanni Vendramin, Santiago C. Gonzalez-Martinez

\section{- To cite this version:}

Juan Jaramillo-correa, Francesca Bagnoli, Delphine Grivet, Bruno Fady, Filippos Aravanopoulos, et al.. Evolutionary rate and genetic load in an emblematic Mediterranean tree following an ancient and prolonged population collapse. Molecular Ecology, 2020, 29, pp.4797-4811. 10.1111/mec.15684 . hal-03025269

\section{HAL Id: hal-03025269 \\ https://hal.inrae.fr/hal-03025269}

Submitted on 21 Oct 2021

HAL is a multi-disciplinary open access archive for the deposit and dissemination of scientific research documents, whether they are published or not. The documents may come from teaching and research institutions in France or abroad, or from public or private research centers.
L'archive ouverte pluridisciplinaire HAL, est destinée au dépôt et à la diffusion de documents scientifiques de niveau recherche, publiés ou non, émanant des établissements d'enseignement et de recherche français ou étrangers, des laboratoires publics ou privés. 
$1 \quad$ Evolutionary rate and genetic load in an emblematic Mediterranean tree following an ancient and prolonged population collapse

3

4 Juan P. Jaramillo-Correa1, Francesca Bagnoli², Delphine Grivet ${ }^{3}$, Bruno Fady ${ }^{4}$, Filippos A. Aravanopoulos ${ }^{5}$, Giovanni G. Vendramin², Santiago C. González-Martínez ${ }^{6, *}$

6

1. Department of Evolutionary Ecology, Instituto de Ecología, Universidad Nacional Autónoma de México, Mexico City, Mexico

2. Institute of Biosciences and Bioresources, Division of Florence, National Research Council, Sesto Fiorentino (FI), Italy

3. Department of Forest Ecology and Genetics, Forest Research Centre, INIA-CIFOR, Madrid, Spain

4. INRAE, Unité de Recherche Écologie des Forêts Méditerranéennes (URFM), Avignon, France

5. Laboratory of Forest Genetics and Tree Breeding, Department of Forestry and Natural Environment, Aristotle University of Thessaloniki, Thessaloniki, Greece 


\section{Abstract}

Severe bottlenecks significantly diminish the amount of genetic diversity and the speed at which it accumulates (i.e. evolutionary rate). They further compromise the efficiency of natural selection to eliminate deleterious variants, which may reach fixation in the surviving populations. Consequently, expanding and adapting to new environments may pose a significant challenge when strong bottlenecks result in genetic pauperization. Herein, we surveyed the patterns of nucleotide diversity, molecular adaptation and genetic load across 177 gene-loci in a circum-Mediterranean conifer (Pinus pinea L.) that represents one of the most extreme cases of genetic pauperization in widespread outbreeding taxa. We found very little genetic variation in both hypervariable nuclear microsatellites (SSRs) and gene-loci, which translated into genetic diversity estimates one order of magnitude lower than those previously reported for pines. Such values were consistent with a strong population decline that began some $\sim 1 \mathrm{Ma}$. Comparisons with the related and parapatric maritime pine (Pinus pinaster Ait.) revealed reduced rates of adaptive evolution ( $\alpha$ and $\omega_{\mathrm{a}}$ ) and a significant accumulation of genetic load. It is unlikely that these are the result from differences in mutation rate or linkage disequilibrium between the two species; instead they are the presumable outcome of contrasting demographic histories affecting both the speed at which these taxa accumulate genetic diversity, and the global efficacy of selection. Future studies, and programs for conservation and management, should thus start testing for the effects of genetic load on fitness, and integrating such effects into predictive models. 


\section{Introduction}

Evolutionary rate, the speed at which genetic diversity accumulates within a species' genome, depends on both the rate at which mutations appear, and the likelihood that they reach fixation (Charlesworth et al. 1995; Eyre-Walker and Keightley 2007;

Charlesworth 2009). This likelihood is conditioned by each mutation's effect on fitness, and stochastic processes that may eliminate them. Consequently, evolution (and adaptation) indirectly relies on species' biological features like population size (or its change over time), migration rate and mating system, which condition both the efficacy of selection and the extent of genetic drift (e.g. Charlesworth 2009; Chen et al. 2017). For instance, deleterious mutations accumulate at very low frequencies in large populations (often in heterozygous states), while they can more easily reach fixation in smaller populations, because of a diminished efficiency of purifying selection (Charlesworth et al. 1993; Eyre-Walker and Keightley 2007). Similarly, advantageous variants may increase in frequency at faster rates in large populations or under elevated gene flow regimes, than in smaller or isolated stands, where they can disappear through the effect of drift (Charlesworth and Eyre-Walker 2007; Eyre-Walker and Keightley 2009).

The consequences of drastic population size reductions on the efficacy of selection and the accumulation of genetic load (the reduction of mean fitness in a population caused by deleterious variation relative to a mutation-free population) are thus fundamental aspects of population genetics (e.g. Kimura et al. 1968; Ohta 1992; Gillespie 2001). They are also of high interest in current conservation, domestication, improvement and clinical genetics projects (e.g. Marsden et al. 2016; Robinson et al. 2016; Pedersen et al. 2017). Theory predicts that neutral variation accumulates proportionally to mutation rate, and independently of population size (Lanfear et al. 2014). As a result, the (neutral) evolutionary rate of population/species should not be 
affected after a bottleneck if mutation rate remains unchanged. However, a negative relationship is expected between the accumulation of deleterious mutations and population size, with larger populations/species purging more efficiently disadvantageous variants than smaller ones (e.g. Chen et al. 2017). Consequently, comparing how different sorts of mutations (neutral vs. putatively deleterious) accumulate in populations/species with contrasting demography may be used as a proxy for inferring adaptive evolutionary rates (e.g. Böndel et al. 2015; GonzálezMartínez et al. 2017; Grivet et al. 2017).

Some studies (e.g. Balloux and Lehmann 2012; Wei et al. 2015) have nevertheless suggested that mutation rate can also be affected by demographic fluctuations, particularly when generations overlap, as in most long-lived taxa, including mammals and forest trees. While such a possibility may flaw the comparisons above, other authors have claimed that it is the generation time that is affected by demographic changes, rather than mutation rate itself (Lanfear et al. 2014). A recent empirical survey on two pines with contrasting demography, and similar generation times and life-history traits, (Grivet et al. 2017) pointed in that direction, as it reports no differences in the rate of evolution between these taxa.

Forest trees are reputed for their resilience to stochastic processes, particularly those derived from population size changes (Petit and Hampe 2006). They have long generation times, extensive gene flow and large reproductive output over the years, which, combined with strong selective pressures at early life stages, reduce the impact of inbreeding depression and maintains (ancestral) genetic diversity (e.g. Ledig et al. 2000). On the other hand, such features also result in a lowered accumulation of mutations per unit of time, which suggests a slow recovering of molecular genetic variation after a strong and prolonged bottleneck (Lanfear et al. 2014; Jaramillo-Correa 
et al. 2015a). Interestingly, these features can also make them more impermeable to the accumulation of genetic load and favour the spread of new advantageous mutations (Petit and Hampe 2006; Lanfear et al. 2014).

Stone pine (Pinus pinea L.) is an emblematic Mediterranean tree that has been associated to humans for thousands of years. For instance, fatty acids related to stone pine nuts have been identified in calculus from hominid teeth remnants more than 300 ka old (Hardy et al. 2015), and charcoal fragments assigned to stone pine have been reported in several human settlements dating back to the last 50 ka (Prada et al. 1997; Badal 1998; Carrión et al. 2008). Archaeological evidence indicates that this species has been cultivated for over 6,000 years (Prada et al. 1997; Pérez-Jordà et al. 2017), and its nuts have been traded since the Phoenician civilization (i.e. 3,500 BP; Wilcox 1977; Popova and Hristova 2017). Stone pine is thus considered an archaeophyte (i.e. a species distinguished by unrecorded early man introductions) currently distributed around the whole Mediterranean basin, where it forms small populations growing on different types of soil, from the sea level up to 1,000 meters (Richardson 1998). Despite this distribution, stone pine is one of the most genetically depauperate outbreeding plants in the world, with virtually no genetic variation at allozyme or chloroplast microsatellite loci (Fallour et al. 1997; Vendramin et al. 2008). These features make stone pine an ideal model for testing hypotheses related to evolutionary rate changes and the accumulation of genetic load after strong and prolonged bottlenecks.

Herein, we collected nuclear microsatellite and DNA sequence data to estimate more accurately the genomic diversity of stone pine and infer its demographic history. For comparison, we used data available for the parapatric sister taxon maritime pine (Pinus pinaster Ait.), which inhabits similar environments but has much higher amounts of genetic diversity (Bucci et al. 2007; Jaramillo-Correa et al. 2015b; Grivet et al. 2017). We 
then determined the accumulation of putatively neutral and deleterious genetic variation since its divergence from maritime pine, by using the distantly related (and native to North America) loblolly pine (Pinus taeda L.) as outgroup. We inferred various evolutionary parameters by taking into account both the shared and exclusive portion of genetic variation to each taxon. We hypothesized that the low effective population size of stone pine resulted in a diminished evolutionary rate and in higher genetic load when compared to maritime pine. However, such values should be different from those expected under a simple bottleneck model with no selection. That is, we expected that purifying selection have managed to purge most of the deleterious part of the genetic load and allowed for the retention of some advantageous variants in stone pine (i.e. the number of fixed adaptive mutations should be different from zero).

\section{Materials and Methods}

\section{Sampling, genotyping and sequencing}

Two datasets were used to infer demographic and population genetic patterns in stone pine. First, nuclear microsatellite (nuSSR) data were obtained for 735 individuals from 33 populations distributed along the species range (Fig. 1A; Table S1). Sample size per population varied between 16 and 30 individuals; all of which were at least $50 \mathrm{~m}$ apart. DNA was extracted from foliage using DNeasy Plant Mini Kits (QIAGEN, Valencia, CA, USA) and amplified using stone pine specific primers for 13 nuSSRs. Primer sequences and PCR conditions are described in Pinzauti et al. (2012). PCR amplification was carried out in a GeneAmp PCR 9700 thermal-cycler (Applied Biosystems, Foster City, California, USA), and PCR products were separated in an ABI 3130xl automatic sequencer (Applied Biosystems). Electrophoregrams were scored using GeneMapper version 4.0 (Applied Biosystems). 
Second, DNA sequences for 264 gene loci originally identified on loblolly pine were obtained for 12 individuals from as many populations dispersed across the full species' range (Fig. 1A; Table S1). Sanger resequencing was performed on haploid seed megagametophytes, which allows for direct phase inference and identification of coamplified gene paralogs. DNA sequences were visually checked and manually edited with SEQUenCHER 4.7 (Gene Codes Corporation, Ann Arbor, MI, USA). Low-quality sequences and those exhibiting double peaks (indicative of paralog co-amplification) were removed, which resulted in a final dataset of 177 gene loci scattered over most pine chromosomes (see Westbrock et al. 2015; Plomion et al. 2016), and covering up to $56 \mathrm{Kbp}$. The retained sequences were aligned with their maritime pine and loblolly pine orthologs, and annotated from homology with EST contigs from the last species and the NCBI reference protein database using GENEIOUS version 6.1 (Biomatters, Auckland, New Zealand).

\section{Genetic diversity and population structure}

For nuSSR data, standard genetic diversity statistics were estimated for each population using GENALEX version 6.503+ (Peakall and Smouse 2006). These included the mean $(A)$ and effective $(A \mathrm{e})$ number of alleles, the number of private alleles, and the observed $\left(H_{0}\right)$ and expected $\left(H_{\mathrm{E}}\right)$ heterozygosity, from which $F$-statistics were computed with FSTAT (Goudet 2002). Deviations from Hardy-Weinberg (H-W) expectations and linkage disequilibrium between loci were also evaluated with GENALEX. Only one locus (pEST2669) showed deviations from $\mathrm{H}-\mathrm{W}$ in over $70 \%$ of the populations and was removed from all analyses. No linkage between pairs of loci was systematically observed. Population clustering and differentiation were evaluated using a principal coordinates analysis (PCoA, performed with GENALEx; Peakall and Smouse 2006), and 
with Bayesian software STRUCTURE (Pritchard et al. 2000). For the latter analysis, ten runs of 1,000,000 iterations of an admixture model with correlated allele frequencies and no priors on population locations were performed for $K$-values ranging from 1 to 13 , after a burn-in period of 500,000 steps. Convergence among runs with the same $K$-value was verified using CLUMPP (Jakobsson and Rosenberg 2007), and the most plausible number of clusters was determined in STRUCTURE HARVESTER (Earl and von Holdt 2011) following Evanno et al. (2005) and Janes et al. (2017).

For the DNA sequence dataset, standard diversity estimates, such as the number of segregating sites $(S)$ and haplotypes $(h), \pi$ (Nei and Li 1979) and Watterson's $\theta_{\mathrm{W}}$ (Watterson 1975) were calculated using DnaSP v.6 (Rozas et al. 2017) for all sites, and separately for synonymous and non-synonymous sites. In addition, the pairwise divergence $\left(D_{\mathrm{xy}}\right)$ from loblolly pine was computed together with the number of synonymous substitutions per synonymous site $\left(K_{s}\right)$ and of non-synonymous substitutions per non-synonymous site $\left(K_{\mathrm{a}}\right)$, both using the Jukes-Cantor correction. To ease some of the demographic and genetic-load inferences below, the two last parameters $\left(K_{\mathrm{s}}\right.$ and $\left.K_{\mathrm{a}}\right)$ were also determined between maritime and loblolly pines. Sequence alignments were also used to separate divergence counts into those that were exclusive to each maritime and stone pines (i.e. that arose after their divergence), and those that were shared between these two taxa (i.e. that appeared before their split but after the separation from their common ancestor with loblolly pine).

\section{Phylogeny and demographic inferences}

The phylogenetic relationships and divergence times between stone, maritime and loblolly pines were co-inferred from a random subset of 50 gene-sequence alignments. This subset was selected to reduce computing time and facilitate convergence among 
partitions and runs. First, the best-fit gene partition, with the corresponding molecular evolution models, was selected based on a Bayesian Information Criterion with PARTITIONFINDER 1.1 (Lanfear et al. 2012) using linked branch lengths and a greedy algorithm. Then, phylogenies were inferred using the Bayesian framework implemented in BEAST v1.7 (Drummond et al. 2013) by assuming a log-normal relaxed molecular clock and specifying $\log$-normal-distributed priors for the parameters, and a Calibrated Yule model for the tree. Following previous phylogenetic work on pines (e.g. Gernandt et al. 2005; Saladin et al. 2017), the divergence between North American loblolly pine (subsect. Autrales) and the two Mediterranean pines (stone and maritime pines; subsect. Pinaster) was calibrated using a log-normal distribution centred at 35 million years ago (Ma) and a $95 \%$ probability interval of $\pm 10 \mathrm{Ma}$; such a calibration covers the subgenus Pinus split, which was dated back to 45Ma based on P. bailey fossils (Saladin et al. 2017). Analyses consisted of ten runs of 100 million iterations each; samples were collected every 1,000 steps after removing the first $25 \%$ of trees as burn-in. Chain mixing, likelihood stability, and convergence across runs were surveyed using TRACER v1.6 (Drummond et al. 2012). Subsampled trees were finally summarized by Maximum Clade Credibility with common ancestor heights as node heights on TREEANNOTATOR 1.8.0 (Drummond et al. 2012).

The demographic history of stone pine was initially surveyed using STAIRWAYPLOT (Liu and Fu 2015), an approach that uses the site frequency spectrum (SFS) to fit a demographic model consisting of population size changes over various periods of time. This analysis was performed from the unfolded SFS derived from all DNA sequences (55,833 sites) and using the median mutation rate inferred on the phylogenetic analyses above (i.e. $4.18 \times 10^{-8}$ per site per generation); as for other pines (Brown et al. 2004; Willyard et al. 2006), a generation time of 25-40 years was assumed. Median values and 
confidence intervals for population size estimates were derived from 200 replicates of the input file using the built-in bootstrap function. Stairway-plots were generated for the whole sample and for each genetic cluster separately (see below).

In addition, and to gain a more detailed insight of the most recent demographic history of stone pine, we tested several potential evolutionary scenarios based on present-day population structure (involving two differentiated genetic clusters for eastern and western Mediterranean populations, see Results), using the approximate Bayesian procedure implemented in DIYABC (Cornuet et al. 2010).

The tested scenarios were as follows (see also Fig. S1, provided as Supplementary Information):

Scenario1 (null hypothesis): no population genetic structure and no population size changes;

Scenario 2 (ancient bottleneck): no population genetic structure and ancient and severe bottleneck;

Scenario 3 (ancient split + bottleneck 1): ancient divergence followed by collapse of both eastern and western Mediterranean genetic clusters;

Scenario 4 (ancient split + bottleneck 2): ancient divergence followed by collapse of the eastern genetic cluster;

Scenario 5 (ancient bottleneck + split): ancient and severe bottleneck predating the divergence of the two genetic clusters;

Scenario 6 (ancient bottleneck + split + recent bottleneck): identical to Scenario 5 but including a collapse for the eastern genetic cluster after divergence.

After fine-tuning prior parameters (all of which had uniform distributions, except for mutation rate, which had a log-uniform distribution), a reference table with one million simulated datasets per scenario was built. Then, the $1 \%$ of these datasets that were the 
closest to the observed data were used to infer the posterior probability of each scenario. Goodness-of-fit was assessed for each scenario by model checking using the Principal Component Analysis (PCA) implemented in DIYABC, which measures the discrepancy between simulated and real data. Confidence in scenario choice (i.e. Type I

249 and II errors) was estimated by simulating 500 datasets under each scenario to determine the probability of not choosing each scenario when it was the true one, or to

choosing it when it was not the true scenario. The most likely scenario was finally

employed to estimate demographic parameters for the two genetic clusters: time in number of generations, and effective sizes for the current and ancestral populations (see Figs. 2 and S1).

\section{Adaptive evolution and accumulation of genetic load}

The proportion of nonsynonymous substitutions fixed by adaptive evolution $(\alpha)$ and the rate of adaptive substitutions scaled by the rate of neutral substitutions $(\omega$ a $)$ were inferred from DNA sequence data using methods available in DOFE 4.0

\section{(http://www.sussex.ac.uk/lifesci/eyre-walkerlab/documents/dofe-31-for-}

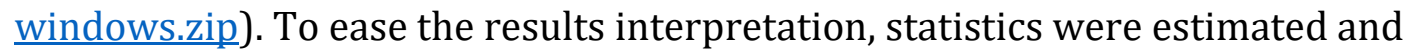
compared between stone and maritime pines by using loblolly pine as an outgroup; only the non-shared part of the divergence (i.e. the fixed exclusive differences for each taxon determined above) from loblolly pine was included in these calculations. Briefly, $\alpha$ was estimated based on Smith and Eyre-Walker (2002), and $\omega$ a was determined using the non-parametric method of Gossman et al. (2010) and method II of Eyre-Walker and Keightley (2009). This last statistic incorporates putative demographic changes that may affect the patterns of nucleotide polymorphism by comparing the observed SFS at neutral sites, with the one expected in a stationary population at equilibrium. This 
method was also used to infer the distribution of fitness effects (DFE) for 0 -fold degenerate mutations exclusive to each species. For stone pine, DFE was estimated for the whole species and for each genetic cluster, and summarized in three bins of increasing purifying selection $\left(0<N_{\mathrm{e}} S<1 ; 1<N_{\mathrm{e}} s<10 ; N_{\mathrm{e}} s>10\right)$.

In addition, the relative proportion of new deleterious mutations that had accumulated since the divergence of each taxa was approximated in two ways. First, the ratio $\pi_{\mathrm{a}} / \pi_{\mathrm{s}}$ (a proxy of the efficacy of selection) was estimated, using loblolly pine as outgroup, from the diversity of 0 -fold and 4-fold positions of all polymorphic coding sequences with only two variants per polymorphic site. Second, the functional effects of all variants (fixed and polymorphic) exclusive to each stone or maritime pines were inferred using PRovEAN (Choi and Chan 2015). This tool uses alignments from protein blasts against public databases to determine a score for any given site change, by assuming that the rarer a mutation is, the most likely it is to be deleterious. It gives particularly low scores to nonsense replacements and to those resulting in substantial biochemical changes, especially in conserved protein regions (Choi and Chan 2015). Following a similar survey in spruce (Conte et al. 2017), variants with scores below 2.282 were retained as deleterious candidates (see also Zhang et al. 2016 for poplar). Candidate counts per species, per gene and per individual were finally compared with non-parametric tests.

\section{Results}

Microsatellite variation and genetic structure

Genetic diversity estimated with nuSSRs was extremely low in stone pine. Four out of the 13 loci surveyed were monomorphic; the nine polymorphic nuSSRs carried between two and five alleles, totalling only 29 size variants (mean $=2.23$ alleles per locus). The 
mean number of alleles per population ranged between 1.00 and 1.69 (mean $=1.38$ ),

296

297 and the average number of effective alleles per population between 1.00 and 1.41 (mean = 1.19; Table S1). In addition, allele frequencies were highly homogeneous across populations. Most loci only displayed one frequent allele common to all populations (frequency $>0.8$ ) and a few rare variants scattered across isolated populations with no apparent geographic trend. Ten out of the 29 alleles observed (34.5\%) were private; four of these were observed in populations from the Iberian Peninsula, although some were also found in France, Tunisia, Lebanon and Turkey (Fig. 1A); two of these private alleles were in homozygous state. Heterozygosity was also very low, ranging from 0.014 and 0.176 for $H_{0}($ mean $=0.083)$ and between 0 and 0.221 for $H_{\mathrm{E}}($ mean $=0.114$; Fig. $1 \mathrm{~A}$; Table S1). Mean population divergence was high $\left(F_{\mathrm{ST}}=0.242\right)$, and the most plausible number of genetic clusters was two (Fig. 2). These clusters were mostly located in the eastern or western parts of the Mediterranean Basin. Increasing $K$-value to three revealed an additional subdivision for the eastern genetic cluster, separating populations from Israel/Lebanon from those of Greece/Turkey; stands from Cyprus were genetically intermixed. $K$-values 4 and 5 revealed no further subdivisions (Fig. S2). For all examined $K$-values, assignment of the Portuguese population and of a Spanish marginal population (Garrovillas, see Fig. 2B) was dubious; they both had a large genetic component from the eastern genetic cluster, suggesting a recent anthropogenic introduction. These populations were removed from further analyses. Similarly weak population genetic structure was observed with the first two coordinates of the PCoA, which explained $44 \%$ and $23.7 \%$ of the data variance, respectively (Fig. S2).

\section{Species divergence and demography}


Only one tree topology was supported by the phylogenetic analyses (posterior probability $=1.0$ for all nodes), indicating (as expected) that stone pine is more closely related to maritime pine than to loblolly pine. Divergence between stone pine and its common ancestor with maritime pine dated back to $29 \mathrm{Ma}(95 \% \mathrm{CI}: 35-12 \mathrm{Ma})$, while its separation from the common ancestor with loblolly pine was inferred in $\sim 40 \mathrm{Ma}$ (95\%CI: 25-52Ma; Fig. 3A).

The demographic history of stone pine, as inferred with STAIRWAYPLOT (on DNA sequence variation), was marked by a deep trend of effective population size decrease starting $\sim 1 \mathrm{Ma}$. This trend was observed for the whole species (Fig. 3C), and for each independent genetic cluster (Fig. S3). For the whole species, a first initial collapse reduced the stone pine population size by about $80 \%$, while two more recent episodes narrowed it down to 1-5\% of its ancestral size during the last 200Ka (Fig. 3C).

Population collapse seemed stronger for the eastern genetic cluster than for the western one (Fig. S3). Interestingly, maritime pine suffered a population size decline of a similar magnitude during this period, from which it was able to recover to approximately ancestral population sizes before the decline (Fig. 3B). No population size recovery was inferred for stone pine.

A more detailed exploration of the recent demographic dynamics of stone pine was performed by testing several hypotheses by approximate Bayesian inference on the nuSSR data. The most likely scenario (scenario 5, see Materials and Methods; Posterior Probability $=0.8$ ) involved a severe bottleneck in the ancestral population, and a more recent population subdivision between the western and eastern genetic clusters, which currently have highly dissimilar population sizes (much larger in the west; Fig. 3D). These episodes were respectively inferred 5,510 and 238 generations into the past. If we consider a generation time of 25-40 years, as for other pines, the ancestral population 
collapse would date back to between $220 \mathrm{Ka}$ and $135 \mathrm{Ka}$, which roughly coincides with the previous interglacial and the second to last glacial period (i.e. the Mindel-Riss interglacial and Riss Glaciation in the Alps), respectively, and with the second population decline inferred from the DNA-sequence data (Fig. 3C). Moreover, population divergence would have occurred during the Holocene (9.5 - 6Ka), roughly coinciding with the earliest fossil evidence of stone pine cultivation (see Discussion).

\section{Nucleotide diversity, adaptive evolution and genetic load}

DNA sequence variation was also extremely low for stone pine (even lower than for the nuSSRs, in comparative terms); only 15 of the 177 gene loci were polymorphic (8.5\%), and contained 21 variable sites, which represents one SNP every $\sim 2.5 \mathrm{Kbp}$. For a comparison, 171 of the same gene loci were polymorphic in maritime pine, and harbored 548 SNPs (one SNP every 102 bp). This translated into a mean nucleotide diversity that was one order of magnitude lower in stone pine $(\pi=0.000212$ [95\% CI: 0.000184-0.000246]; $\theta_{\mathrm{w}}=0.000149$ [95\%CI: 0.000126-0.000178]) than in maritime pine $(\pi=0.002423$ [95\%CI: 0.002065-0.002778]; $\theta \mathrm{w}=0.002305$ [95\%CI: 0.001993-0.002621]; Table 1). Both $\pi$ and $\theta$ w estimates were equally low and not significantly different between the two stone pine genetic clusters (Table S2).

Despite this very low nucleotide diversity, the mean rate of total $\left(D_{\mathrm{xy}}\right)$, synonymous $\left(K_{\mathrm{s}}\right)$ and non-synonymous substitutions $\left(K_{\mathrm{a}}\right)$ accumulated in stone pine since its divergence from loblolly pine (0.0168 [95\%CI: 0.0147-0.0185], 0.0382 [95\%CI: 0.0338-0.0426], 0.0099 [95\%CI: 0.0073-0.0116]; respectively) were virtually identical to those observed for maritime pine $\left(D_{\mathrm{xy}}=0.0164\right.$ [95\%CI: $\left.0.0146-0.0182\right] ; K_{\mathrm{s}}=0.0384$ [95\%CI: 0.0336-0.0432]; $K_{\mathrm{a}}=0.0101$ [95\%CI: 0.00836-0.0118]). Decomposing these figures revealed that they were mostly due to the number of shared substitutions 
between species (Fig. 4). The non-shared portion was significantly smaller in stone pine than in maritime pine, and it was composed of a relatively similar number of synonymous and non-synonymous substitutions (152 vs. 113). In maritime pine, the non-shared variants contained almost twice as many silent than replacement substitutions (325 vs. 188; Fig. 4). Such values translated in a larger $K_{\mathrm{a}} / K_{\mathrm{s}}$ ratio (estimated per gene) for stone pine than for maritime pine $(0.46$ [95\%CI: $0.41-0.52]$ vs. 0.33 [95\%CI: 0.24-0.40]), suggesting relaxed purifying selection in stone pine (Table 1). The efficacy of selection, as determined with the $\pi_{\mathrm{a}} / \pi_{\mathrm{s}}$ ratio, pointed in the same direction, as estimates were again higher in stone pine (0.448 [95\%CI: 0.371-0.526]) than in maritime pine (0.256 [95\%CI: 0.186-0.326]; Table 1). As for nucleotide diversity, no differences were observed for $K_{\mathrm{a}} / K_{\mathrm{s}}$ and $\pi_{\mathrm{a}} / \pi_{\mathrm{s}}$ ratios between stone pine genetic clusters (Table S2).

In terms of adaptive evolution, stone pine also seemed hampered when compared to maritime pine, not only because the proportion of (non-shared) non-synonymous substitutions fixed by adaptive evolution $(\alpha)$ and the relative rate of (non-shared) adaptive substitutions $\left(\omega_{\mathrm{a}}\right)$ were both significantly lower, but because they were also not significantly different from zero; estimates of $\alpha$ and $\omega_{\text {a }}$ were respectively 0.171 (95\%CI: -0.027-0.309) and 0.062 (95\%CI: -0.001-0.119) for stone pine, while they were 0.494 (95\%CI: 0.346-0.609) and 0.304 (95\%CI: 0.219-0.391) for maritime pine (Fig. 4). Estimates of $\alpha$ and $\omega_{\text {a }}$ were virtually identical for both stone pine genetic clusters (Table S2). On the other hand, the general shape of the distribution of fitness effects (DFE) was similar for both stone and maritime pines. However, the first species had a significantly higher proportion of least deleterious mutations (Fig. 4), while maritime pine had a higher proportion of highly deleterious mutations. Again, no differences were observed between stone pine eastern and western genetic clusters. It must be reminded that all 
calculations above for stone and maritime pines (i.e. DFE, $\alpha, \omega_{\mathrm{a}}, K_{\mathrm{a}} / K_{\mathrm{s}}$ and $\pi_{\mathrm{a}} / \pi_{\mathrm{s}}$ ) were performed using only exclusive polymorphisms and replacements accumulated after the divergence from loblolly pine.

Finally, genetic load, evaluated as the predicted number and frequency of non-shared replacements with putatively deleterious effects according to PRoveAn (Choi and Chan 2015), was higher in stone pine than in maritime pine. The first species accumulated relatively less replacements (116) and in less genes (20) than maritime pine (166 replacements in 38 genes; Mann-Whitney U-test; $P=0.0394$ and $P=0.0142$ for the number of replacements and genes, respectively). However, 34 of the replacements observed in stone pine (29.3\% of the total) were putatively deleterious, and most of them (27 out of the 34 ; or $23.3 \%$ of the total substitutions) were fixed in the individuals analysed (Fig. 4). On the other hand, 48 (28.9\%) putatively harmful replacements were inferred for maritime pine, while only 15 of them ( $9 \%$ of the total substitutions) were fixed (Fig. 4). Both the total number of putatively deleterious mutations and the number of fixed deleterious mutations were significantly different between the two pines (Mann-Whitney U-test; $P=0.0271$ and $P=0.0128$, respectively).

Differences in genetic load were more evident when evaluated at the individual level. In stone pine, individuals had on average 0.22 putatively deleterious mutations per gene, while they were significantly less (mean $=0.15$ ) in maritime pine (Mann-Whitney U-test; $P=0.0184)$. After scaling by the number of synonymous mutations per species, the mean number of putatively deleterious mutations per gene per individual was still significantly higher for stone pine (0.042) than for maritime pine (0.019; Mann-Whitney U-test; $P=0.0036$ ), indicating relaxed purifying selection in the first species. Interestingly, deleterious variants were not equally distributed across polymorphic and monomorphic genes in stone pine (Table S3), particularly those that were fixed for 
significantly more replacement substitutions than the average gene (i.e. five or more replacements; $n=39)$. More than half of the polymorphic genes (53\%) contained putatively deleterious variants, while only a fifth of the monomorphic genes bearing five or more replacements exhibited such harmful variants (Mann-Whitney U-test; $P=$ 0.0083). These monomorphic genes with reduced fixation of deleterious mutations were further biased towards regulation and stress response processes and have often been reported as candidate genes for adaptation in other pines (see Discussion), while the polymorphic genes showed no particular function enrichment (Table S3).

\section{Discussion}

In this study, we demonstrate that the widespread and outbreeding stone pine has unprecedentedly low genome-wide levels of genetic diversity. This near absence of genomic variation is the product of a deep and prolonged demographic collapse, rather than changes in the speed at which it accumulates genetic diversity. This demographic framework further resulted in a lowered efficacy of purifying selection and the fixation of deleterious variants.

Low levels of genome-wide genetic diversity and phylogeographic inferences In line with previous studies on allozymes (Fallour et al. 1997) and chloroplast microsatellites (cpSSRs) (Vendramin et al. 2008), we found very little genetic variation in both hypervariable nuclear microsatellites (29 alleles in 13 nuSSRs) and gene loci (21 SNPs in 177 gene loci spanning more than $55 \mathrm{Kbp})$. While estimation accuracy of individual parameters might be at stake because of our relatively small dataset (both in terms of markers and sample size), it is unlikely that such low diversity values are the result of limited population or genome sampling. Indeed, both population genetics and 
coalescence theory indicates that much of the genetic variability within a species can be captured with a limited number of individuals, while strong demographic changes affecting the whole genome can be detected even when surveying a modest part of the genome (Tajima 1983; Nielsen and Slatkin 2013).

In plants, low diversity values are usually observed in self-fertilizing taxa or in species with very restricted distributions, but are unusual in widespread outbreeding taxa (Table 2). Within the genus Pinus, and forest trees in general, estimates of genomic diversity are usually much higher than those obtained herein for stone pine $(\pi=$ 0.0002), even for endemic species, such as P. balfouriana $(\pi=0.0028)$ or $P$. longaeva $(\pi=$ 0.0021; Eckert et al. 2013). Indeed, to our knowledge, the only conifer for which such an equally low nucleotide diversity has been reported is the tertiary relict Picea breweriana ( $\pi=0.0001$; Chen et al. 2010), which is distributed in small scattered stands at the border between California and Oregon.

Previous works have suggested an ancient and prolonged bottleneck to account for the low genetic variation in stone pine, but without providing further insights on times or population sizes (Fallour et al. 1997; Vendramin et al. 2008). Our demographic framework indicated a general and strong trend of population collapse that could have started as early as $\sim 1 \mathrm{Ma}$, reduced the ancestral stone pine population to $1-10 \%$ of its original effective size, and continued well within the Holocene (Fig. 3). The number and timing of decline pulses vary according to the type of marker (SSRs vs. gene-loci) and method used (ABC vs. SFS-based), but they all coincide with glacial periods of the Pleistocene (e.g. Günz, Riss, and Würm; Cohen and Gibbard 2011; Fig. 3). While such differences might be the result of our limited sample size, variation in demographic parameters is rather common when using different markers and methods (e.g. Patton et 
al. 2019). This deserves a more detailed study, likely including simulations, which is out of the scope of the present work.

In addition to demographic history, some biological features of stone pine, such as its inability to disperse its seeds by wind (contrarily to other Mediterranean pines) or the 3-year cone maturation (all other Mediterranean pines take only two years), may have also contributed to its unusually low genetic diversity. For example, because of restricted gene flow, all mutations that appeared after or during the population decline would have been only locally dispersed, increasing their chances to be lost by genetic drift. Ancient alleles would have suffered a similar fate, being differentially fixed or lost, but never dispersed among distant populations. Indeed, such a feature can also explain the genetic structure of stone pine, which is mostly driven by private nuSSR alleles, whose spatial distribution (together with that of polymorphic SNPs and rare cpDNA haplotypes; see Vendramin et al. 2008) could be mostly the result of restricted gene flow among populations.

According to our Bayesian simulations, the main genetic clusters of stone pine did not diverge until the Holocene ( 9 - 6.5 Ka; Fig. 3), while none of the main genetic clusters showed signs of expansion. This implies that stone pine should have colonized its current distribution very quickly. However, its low seed dispersal ability hints that a circum-Mediterranean colonization could not have occurred without the support of idiosyncratic dispersers (Vendramin et al. 2008). Evidence indicates that stone pine seeds have been consumed by humans since at least $\sim 50 \mathrm{Ka} \mathrm{BP,} \mathrm{that} \mathrm{it} \mathrm{has} \mathrm{been}$ cultivated for over 6,000 years, and its nuts traded during no less than three millennia (Prada et al. 1997; Badal 1998; Carrión et al. 2008; Pérez-Jordà et al. 2017). Estimated divergence times between genetic clusters roughly coincide with the beginning of stone pine cultivation, which points at anthropogenic factors as the main drivers of recent 
expansion, divergence and ecological success (Barbero et al. 1998; Richardson, 1998; Vendramin et al. 2008).

Archeological remnants and analyses of ancient trade routes further suggest that the ancestral stone pine population (from where colonization took place) was likely located within the Iberian Peninsula (Carrión et al. 2008; Mutke et al. 2019; Fig. 3.4 from Rubiales et al. 2011); a view supported by the distribution of private nuSSR alleles (Fig. 1) and rare cpDNA types (Vendramin et al. 2008), and by the higher effective population sizes estimated herein for the western genetic cluster (Fig. 3D). Unfortunately, the low genetic diversity of this species hampers for the time being more detailed phylogeographic and genomic analyses (including the putative effects of incipient domestication for nut taste and size).

\section{Evolutionary rates and adaptive variation}

Our estimates of adaptive evolution ( $\alpha, \omega$ a, and DFE) pointed to a diminished (adaptive) evolutionary rate in stone pine when compared to maritime pine, as well as a relaxation of purifying selection (Table 1; Fig. 4). These results agree with theoretical expectations, implying less potential for adaptive evolution in species with small effective population size (i.e. stone pine). Although limited by our rather modest genome sampling, $\pi_{\mathrm{a}} / \pi_{\mathrm{s}}, \alpha$

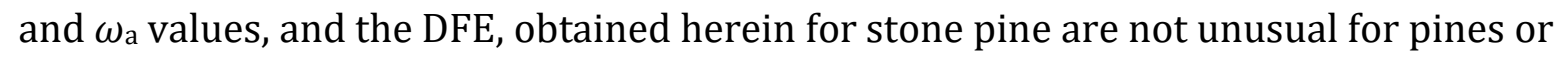
plants in general (Gossman et al. 2010; Chen et al. 2017; Grivet et al. 2017). The nearly neutral theory of molecular evolution predicts a simple relationship between adaptive evolution and effective population size, which can be derived into a $\log$-log linear correlation between $\pi_{\mathrm{s}}$ and $\pi_{\mathrm{a}} / \pi_{\mathrm{s}}$ (Kimura 1968; Welch et al. 2008). Such a relationship was indeed reported for a wide variety of organisms (Chen et al. 2017), and the values obtained herein for stone pine fit well within this regression line (Fig. S4). Thus, current 
effective population size resulting from the peculiar demography of this species seems to account for both the rate at which it is accumulating genetic diversity, and the global efficacy of selection. Because, the sequenced gene-loci were widespread within the stone pine genome, it is unlikely that sequencing additional genes would reverse the patterns observed herein.

It could be argued that other elements, such as variation in mutation rate $(\mu)$ and linkage disequilibrium (LD), or spatiotemporal changes of fitness effects, may underlie observed differences between stone and maritime pines. For instance, it has been suggested that demographic fluctuations can affect $\mu$, particularly in species with overlapping generations (Balloux and Lehmann 2012; Wei et al. 2015). Although we did not formally estimate this parameter, no significant differences were observed between the two pines for $D_{\mathrm{xy}}, K_{\mathrm{a}}$ or $K_{\mathrm{s}}$, which suggest that their mutation rates should be at least in the same order of magnitude. Indeed, to our knowledge, no differences in mutation rates have been reported so far among pine taxa, including those from different subsections (Willyard et al. 2009).

Linkage disequilibrium can cause selection at one locus to affect the fixation of mutations in neighbouring genomic regions (i.e. interference; Lanfear et al. 2014). Conifers are among the plants with the lowest genome-wide recombination rates (Jaramillo-Correa et al. 2010b), which indicates that interference should be indeed taken into account. Unfortunately, because of its low diversity, no reliable recombination inference could be performed herein for stone pine. However, given that fixations between loci (including both nuSSRs and gene-sequences) appeared independent from each other, and that even modest amounts of recombination can be sufficient to alleviate interference (Presgraves 2005; Weissman and Barton 2012), the contribution of LD variation to explain observed differences across stone and maritime pines should be 
negligible. Future studies with more complete genome data are however necessary to test this hypothesis more formally.

Selective pressures may also vary across a species range and over time, having heterogeneous effects on substitutions rates, and thus on evolutionary rate (Bell 2010). However, if our demographic and phylogeographic inferences are correct, such changes should be affecting more maritime pine than stone pine; given that the first species is composed by six ancient genetic clusters distributed across contrasting environments (Bucci et al. 2007; Jaramillo-Correa et al. 2015b), while population structure in stone pine is less marked and more recent (Fig. 3). While there is still little information on how spatiotemporal variation of fitness affects evolutionary rate (Lanfear et al. 2014), no differences in the proportion of adaptive substitutions were observed across the more ancient maritime pine gene pools (Grivet et al. 2017). Thus, suggesting again that differences in demography appear as the most likely explanation for the contrasting rates at which these two parapatric pines are accumulating genetic diversity.

Genomes of heavily bottlenecked species usually exhibit overall genetic depletion, with isolated and randomly distributed peaks of diversity (Robinson et al. 2016). Stone pine seems to fit such expectations. The few SNPs detected were distributed in only 15 genes that were not particularly biased towards specific biological processes. They participated in functions as varied as transport, ATP binding and secondary metabolism, and are scattered in various pine linkage groups (Westbrock et al. 2015; Plomion et al. 2016). More than half of these genes (53\%) contained putatively deleterious variants (either fixed or polymorphic; Table S3).

Interestingly, among the monomorphic genes, those that were fixed for significantly more replacement substitutions than the average gene (i.e. five or more replacements; $n=39$ ) tended to have fewer deleterious variants. These genes were further enriched 
towards regulation and stress response processes, and most of them (60\%) have been reported as candidate genes for local adaptation in other pines and/or are upregulated under drought stress in stone pine (Perdiguero et al. 2013; Table S3). Although these observations are preliminary, given the modest gene sampling of our study and the lack of current knowledge on gene function in conifers, they do provide an interesting starting point to understand how adaptive variation arises and reaches fixation in these taxa.

\section{Long-term persistence in the absence of genetic variation}

An interesting question that arises from our study is how a species genetically depleted has been able to survive, thrive, and successfully compete with taxa that occupy a similar ecological niche. Extrapolating from the limited number of genes surveyed, maritime pine bore significantly more silent and replacement substitutions and more putatively harmful mutations than stone pine. The large majority of these changes (91\%) were in a heterozygous state in maritime pine, whereas most of the nonsynonymous substitutions detected for stone pine, including many evaluated as deleterious, were homozygous (Fig. 4). These results fit the expectations of a differential accumulation of neutral and putatively deleterious mutations within a species after a bottleneck (Gillespie 2001; Lanfear et al. 2014; Chen et al. 2017), and it is unlikely that this trend could be reversed when additional gene-regions are sequenced.

The accumulation of partially deleterious mutations in stone pine also points to reduced inbreeding depression. In forest trees, this phenomenon generally results in the elimination of virtually all inbred progeny at early life-stages (Petit and Hampe 2006), which is believed to be homozygous for recessive deleterious mutations. When populations are large (as for maritime pine), deleterious mutations tend to accumulate 
593

594

595

596

597

598

599

600

601

602

603

604

605

606

607

608

609

610

611

612

613

614

615

616

617

in heterozygous states. However, after a bottleneck (as for stone pine), these mutations are exposed and can be purged more efficiently, which leads to inbreeding tolerance (i.e. inbreds are no longer selected against), and to a more accelerated diversity loss by genetic drift (Lanfear et al. 2014). Early work in stone pine and other genetically depleted conifers seem to point in that direction (Ammannati 1989; Ledig et al. 2000).

It must be noted, however, that genetic load in stone pine is likely underestimated because of our limited genome sampling, and because virtually all mutations evaluated as deleterious came from bioinformatics predictions. That is, they were either very rare within conifer databases or produced biochemical changes in the proteins. No strongly harmful mutations, like premature stop codons or insertions changing the protein reading frames, were observed in stone pine. While such types of mutations might be detected with a more in-depth genome survey, they are also expected to be more common in species with lower inbreeding depression than forest trees, such as annual plants or vertebrates, including humans (Robinson et al. 2016; González-Martínez et al. 2017; Pedersen et al. 2017; Laenen et al. 2018). Should this trend be confirmed after a more extensive exome re-sequencing, it will indicate that purifying selection is still operating for highly-deleterious variants in stone pine, as could be inferred from the DFE (Fig. 4).

Another mechanism fostering stone pine long-term persistence despite depleted genetic variation might be the presence of islands of genetic diversity within its genome, and which may be associated to relevant adaptive quantitative genetic variation and/or phenotypic plasticity (Carrasquinho and Gonçalves 2013; Mutke et al. 2013; SánchezGómez et al. 2011). Typically, this type of variation is produced by small allele frequency changes in multiple loci across the genome (Pritchard et al. 2010; Boyle et al. 2017; Csilléry et al. 2018); variation that is better preserved during bottlenecks by balancing 
or frequency-dependent selection than newly arisen mutations (Lynch 1996). If this is the case for stone pine, a more detailed genomic survey (including full genome or transcriptome sequencing) should reveal further diversity-rich regions upon which selection may operate. Another possibility is methylation diversity, which has already been shown to be substantial in stone pine (Sáez-Laguna et al. 2014). Such variability is often inheritable, and can rapidly accumulate after bottlenecks and contribute to phenotypic plasticity in adaptive traits (Chinnusamy and Zhu 2009; Johaness et al. 2009; Balao et al. 2018).

Finally, future studies should formally survey the effects on fitness (e.g. via association with adaptive phenotypes, as in Zhang et al. 2016) of the putatively deleterious variants inferred in this study; given that these are merely bioinformatics predictions (Choi and Chan 2015; Conte et al. 2017). Integrating such effects, and genetic load, into predictive models should become a priority for the improvement of commercially important traits in stone pine, such as those related to nut production (see Wallace et al. 2018). Considering deleterious variants is also important for conservation and management programs in forest trees (Holliday et al. 2017). Indeed, avoiding deleterious alleles, especially in homozygosity, might account for a larger part of the phenotypic variance of species than the avidly-searched adaptive genes usually reported in most population genomic studies.

\section{Acknowledgements}

We are grateful to Diana Barba and Denis Vauthier for sampling, and Carmen GarcíaBarriga and Mario Zabal-Aguirre for laboratory assistance and DNA sequence edition. We further thank Yoshiaki Tsuda for help with ABC analyses and Michele Bozzano for stimulating and passionate discussions on stone pine demographic history. Samples 
643

644

645

646

647

648

649

650

651

652

653

654

655

656

657

658

659

660

661

662

663

664

665

666

were collected from common gardens in France and Spain, installed within the FAO-

Silva Mediterranea collaborative framework. French common gardens belong to the

GEN4X network (http://www.efpa.inra.fr/Outils-et-Ressources/Systemes-d-

experimentation-et-d-observation/Reseau-GEN4X/). This research was supported by

funding from EVOLTREE (www.evoltree.eu), a former EU Network of Excellence, and

currently a European Research Group facilitated by the European Forest Institute (EFI),

and B4EST, a project funded by the European Union's Horizon 2020 research and

innovation programme under grant agreement No 773383. JPJ-C was supported by the

“Dirección General de Asuntos del Personal Académico" (DGAPA-UNAM) through a

PASPA fellowship, for a sabbatical leave during which this study was elaborated.

\section{Data accessibility}

Nuclear microsatellite (nuSSR) data, DNA sequence alignments, gene annotations, and site type counts are available in Dryad, with doi: 10.5061/dryad.59zw3r23r.

\section{Author contributions}

JPJC, GGV and SCGM conceived the study. GGV, BF, SCGM, DG and FAA produced the data. DG and FB contributed to data analyses. JPJC and SCGM analysed the data and drafted the manuscript. All authors revised and edited the text, and produced the final manuscript.

\section{References}

Ammannati, R. (1988). Effeti dell'autoimpollinazione sulla crescita in alteza in Pinus pinea L. Monti e Boschi, 3, 50-52. 
Badal, E. (1998). Interés económico del pino piñonero para los habitantes de la Cueva de Nerja. In J.L. Sanchidrián, \& M.D. Simón (Eds.), Las culturas del Pleistoceno Superior en Andalucía (pp. 287-300). Málaga: Patronato de la Cueva de Nerja.

Balao, F., Paun, O., \& Alonso, C. (2018). Uncovering the contribution of epigenetics to plant phenotypic variation in Mediterranean ecosystems. Plant Biology, 20, 38-49.

Balloux, F., \& Lehmann, L. (2012). Substitution rates at neutral genes depend on population size under fluctuating demography and overlapping generations. Evolution, 66, 605-611.

Barbéro, M., Loisel, R., Quézel, P., Richardson, D.M., \& Romane, F. (1998). Pines of the Mediterranean basin. In D.M. Richardson (Ed.), Ecology and biogeography of Pinus (pp. 153-170). Cambridge: Cambridge University Press.

Bazile-Robert, E. (1981). Le pin pignon (Pinus pinea L.) dans le Würm récent de Provence. Géobios, 14, 395-397.

Bell, G. (2010). Fluctuating selection: the perpetual renewal of adaptation in variable environments. Philosophical Transactions of the Royal Society of London, Series B: Biological Sciences, 365, 87-97.

Böndel, K.B., Lainer, H., Nosenko, T., Mboup, M., Tellier A., \& Stephan, W. (2015). NorthSouth colonization associated with local adaptation of the wild tomato species Solanum chilense. Molecular Biology and Evolution, 32, 2932-2943.

Boraks, A., \& Broders, K.D. (2016). Population genetic diversity of the rare hardwood butternut (Juglans cinerea) in the northeastern USA. Tree Genetics \& Genomes, 12, 43. Boyle, E.A., Li, Y.I., \& Pritchard, J.K. (2017) An expanded view of complex traits: from polygenic to omnigenic. Cell, 169, 1177-1186.

Boys, J., Cherry, M., \& Dayanandan, S. (2005). Microsatellite analyses reveals genetically distinct populations of red pine (Pinus resinosa, Pinaceae). American Journal of Botany, 92, 833-841.

Bromham, L., Hua, X., Lanfear, R., \& Cowman, P.F. (2015). Exploring the relationships between mutation rates, life history, genome size, environment, and species richness in flowering plants. The American Naturalist, 185, 507-524.

Brown, G. R., Gill, G. P., Kuntz, R. J., Langley, C. H., \& Neale, D.B. (2004). Nucleotide diversity and linkage disequilibrium in loblolly pine. Proceeding of the National Academy of Sciences of USA, 101, 15255-15260. 
Bucci, G., González-Martínez, S.C., Le Provost, G., Plomion, C., Ribeiro, M.M., Sebastiani, F., Alia, R.,\& Vendramin, G.G. (2007). Range-wide phylogeography and gene zones in Pinus pinaster Ait. revealed by chloroplast microsatellite markers. Molecular Ecology, 16, 2137-2153.

Carrasquinho, I., \& Gonçalves, E. (2013). Genetic variability among Pinus pinea L. provenances for survival and growth traits in Portugal. Tree Genetics \& Genomes, 9, 855-866.

Carrión, J.S., Finlayson, C., Fernández, S., Finlayson, G., Allué, E., López Sáez, J.A., López García, P., Gil-Romera, G., Bailey G., \& González-Sampériz, P. (2008). A coastal reservoir of biodiversity for Upper Pleistocene human populations: palaeoecological investigations in Gorham's Cave (Gibraltar) in the context of the Iberian Peninsula. Quaternary Sciences Reviews, 27, 2118-2135.

Charlesworth, B. (2009). Fundamental concepts in genetics: effective population size and patterns of molecular evolution and variation. Nature Reviews, Genetics, 10, 195205.

Charlesworth, B., Morgan, M.T., \& Charlesworth, D. (1993). The effect of deleterious mutations on neutral molecular variation. Genetics, 134, 1289-1303.

Charlesworth, D., Charlesworth, B., \& Morgan, M.T. (1995). The pattern of neutral molecular variation under the background selection model. Genetics, 141, 1619-1632.

Charlesworth, J., \& Eyre-Walker, A. (2007). The other side of the nearly neutral theory, evidence of slightly advantageous backmutations. Proceedings of the National Academy of Sciences of USA, 104, 16992-16997.

Chen, J., Källman, T., Gyllenstrand, N., \& Lascoux, M. (2010). New insights on the speciation history and nucleotide diversity of three boreal spruce species and a Tertiary relict. Heredity, 104, 3-14.

Chen, J., Glémin, S., \& Lascoux, M. (2017). Genetic diversity and the efficacy of purifying selection across plant and animal species. Molecular Biology and Evolution, 34, 14171428.

Chinnusamy, V., \& Zhu, J.K. (2009). Epigenetic regulation of stress responses in plants. Current Opinion in Plant Biology, 12, 133-139.

Choi, Y., \& Chan, A.P. (2015). PROVEAN web server: a tool to predict the functional effect of amino acid substitutions and indels. Bioinformatics, 31, 2745-2747. 
Cohen, K.M., \& Gibbard, P. (2011). Global chronostratigraphical correlation table for the last 2.7 million years. Cambridge: Subcommission on Quaternary Stratigraphy (International Commission on Stratigraphy). Retrieved from http://quaternary.stratigraphy.org/charts/

Conte, G.L., Hodgins, K.A., Yeaman, S., Degner, J.C., Aitken, S.N., Rieseberg, L.H., \& Whitlock, M.C. (2017). Bioinformatically predicted deleterious mutations reveal complementation in the interior spruce hybrid complex. BMC Genomics, 18, 970.

Cornuet, J. M., Pudlo, P., Veyssier, J., Dehne-Garcia, A., Gautier, M., Leblois, R., ... Estoup, A. (2014). DIYABC v2.0: A software to make approximate Bayesian computation inferences about population history using single nucleotide polymorphism, DNA sequence and microsatellite data. Bioinformatics, 30, 1187- 1189.

Csilléry, K., Rodríguez-Verdugo, A., Rellstab, C., \& Guillaume F. (2018). Detecting the genomic signal of polygenic adaptation and the role of epistasis in evolution. Molecular Ecology, 27, 606-612.

Cuenca, A. (2003) Evidencia de dos linajes genéticos en Pinus cembroides revelada por microsatélites de cloroplasto (Unpublished MSc thesis). Universidad Nacional Autónoma de México.

Drummond, A.J., Suchard, M.A., Xie, D., \& Rambaut, A. (2012). Bayesian Phylogenetics with BEAUti and the BEAST 1.7, Molecular Biology and Evolution, 29, 1969-1973.

Earl, D.A., \& vonHoldt, B.M. (2012). STRUCTURE HARVESTER: a website and program for visualizing STRUCTURE output and implementing the Evanno method. Conservation Genetics Resources, 4, 359-361.

Echt, C.S, De Verno, L.L., Anzidei, M., \& Vendramin, G. G. (1998). Chloroplast microsatellites reveal population genetic diversity in red pine, Pinus resinosa Ait. Molecular Ecology, 7, 307-316.

Eckert, A. J., Bower, A. D., Jermstad, K. D., Wegrzyn, J. L., Knaus, B. J., Syring, J. V., \& Neale, D. B. (2013). Multilocus analyses reveal little evidence for lineage-wide adaptive evolution within major clades of soft pines (Pinus subgenus Strobus). Molecular Ecology, 22, 5635-5650.

Evanno, G., Regnaut, S., \& Goudet, J. (2005). Detecting the number of clusters of individuals using the software structure: a simulation study. Molecular Ecology, 14, 2611-2620 
Eyre-Walker, A., \& Keightley, P.D. (2007). The distribution of fitness effects of new mutations. Nature Reviews, Genetics, 8, 610-618.

Eyre-Walker, A., \& Keightley, P.D. (2009). Estimating the rate of adaptive molecular evolution in the presence of slightly deleterious mutations and population size change. Molecular Biology and Evolution, 26, 2097-2108.

Fallour, D., Fady, B., \& Lefèvre, F. (1997). Study on isozyme variation in Pinus pinea L.: evidence for low polymorphism. Silvae Genetica, 46, 201-207.

Gaut, B.S., Díez, C.M, \& Morrell, P.L. (2015). Genomics and the contrasting dynamics of annual and perennial domestication. Trends in Genetics, 31, 709-719.

Gernandt, D.S., López, G.G., García, S.O. \& Liston, A. (2005). Phylogeny and classification of Pinus. Taxon, 54, 29-42.

Gillespie, J. H. (2001). Is the population size of a species relevant to its evolution? Evolution, 55, 2161-2169.

González-Martínez, S.C., Ridout, K., \& Pannell, J.R. (2017). Range expansion compromises adaptive evolution in an outcrossing plant. Current Biology, 27, 2544-2551.

Gossmann, T.I., Song, B.-H., Windsor, A.J., Mitchell-Olds, T., Dixon, C.J., Kapralov, M.V., ... Eyre-Walker, A. (2010). Genome wide analyses reveal little evidence for adaptive evolution in many plant species. Molecular Biology and Evolution, 27, 1822-1832.

Goudet J. (2002). FSTAT, A program to estimate and test gene diversities and fixation indices. Retrieved from http://www2.unil.ch/popgen/softwares/fstat.htm

Grivet, D., Avia, K., Vaattovaara, A., Eckert, A.J., Neale, D. B., Savolainen, O., \& GonzálezMartínez, S.C. (2017). High rate of adaptive evolution in two widespread European pines. Molecular Ecology, 26, 6857-6870.

Hardy, K., Radini, A., Buckley, S., Sarig, R., Copeland, L., Gopher, A., \& Barkai, R. (2016). Dental calculus reveals potential respiratory irritants and ingestion of essential plantbased nutrients at Lower Palaeolithic Qesem Cave Israel. Quaternary International, 398, 129-135.

Holliday, J.A., Aitken, S.N., Cooke, J.E.K., Fady, B., González-Martínez, S.C., Heuertz, M., Jaramillo-Correa, J.P., Lexer, C., Staton, M., Whetten, R.W., \& Plomion, C. (2017). Advances in ecological genomics in forest trees and applications to genetic resources conservation and breeding. Molecular Ecology, 26, 706-717. 
Jakobsson, M., \& Rosenberg, N.A. (2007). CLUMPP: a software matching and permutation program for dealing with label switching and multimodality in analysis of population structure. Bioinformatics, 23, 1801-1806.

Janes, J.K., Miller, J.M., Dupuis, J.R., Malenfant, R.M., Gorell, J.C., Cullingham, C.I., \& Andrew, R.L. (2017). The K=2 conundrum. Molecular Ecology, 26, 3594-3602.

Jaramillo-Correa, J.P., Gérardi, S., Beaulieu, J., Ledig, F.T., \& Bousquet, J. (2015a). Inferring and outlining past population declines with linked microsatellites: a case study in two spruce species. Tree Genetics \& Genomes, 11, 9.

Jaramillo-Correa, J.P., Rodríguez-Quilón, I., Grivet, D., Lepoittevin, C., Sebastiani, F., Heuertz, M., Garnier-Géré, P., Alía, R., Plomion, C., Vendramin, G.G., \& GonzálezMartínez, S.C. (2015b). Molecular proxies of climate maladaptation in a long-lived tree (Pinus pinaster Aiton, Pinaceae). Genetics, 199, 793-807.

Jaramillo-Correa, J.P., Grivet, D., Terrab, A., Kurt, Y., de Lucas, A.I., Wahid, N., Vendramin, G.G., \& González-Martínez, S.C. (2010a). The Strait of Gibraltar as a major biogeographic barrier in Mediterranean conifers: a comparative phylogeographic survey. Molecular Ecology, 19, 5452-5468.

Jaramillo-Correa, J.P., Verdú, M., \& González-Martínez, S.C. (2010b). The contribution of recombination to heterozygosity differs among plant evolutionary lineages and lifeforms. BMC Evolutionary Biology, 10, 22.

Johannes, F., Porcher, E., Teixeira, F.K., Saliba-Colombani, V., Simon M, Agier, N., ... Colot, V. (2009). Assessing the impact of transgenerational epigenetic variation on complex traits. PLoS Genetics, 5, e1000530.

Kern, A.D., \& Hahn M.W. (2018). The Neutral Theory in Light of Natural Selection. Molecular Biology and Evolution, 35, 1366-1371.

Kimura, M. (1968) Evolutionary rate at the molecular level. Nature, 217, 624-626.

Laenen, B., Tedder, A., Nowak, M.D., Toräng, P., Wunder, J., Wötsel, S., ... Slotte, T. (2018). Demography and mating system shape the genome-wide impact of purifying selection in Arabis alpina. Proceedings of the National Academy of Sciences of USA, 115, 816-821.

Lanfear, R., Kokko, H., \& Eyre-Walker, A. (2014). Population size and the rate of evolution. Trends in Ecology and Evolution, 29, 33-41.

Ledig, F.T, Bermejo-Velázquez, B., Hodgskiss, P.D., Johnson, D.R., Flores-López, C., \& Jacob-Cervantes, V. (2000). The mating system and genic diversity in Martínez spruce, an extremely rare endemic of México's Sierra Madre Oriental: an example of 
facultative selfing and survival in interglacial refugia. Canadian Journal of Forest Research, 30, 1156-1164.

Lemieux, M.J., Beaulieu, J., \& Bousquet, J. (2011). Chloroplast DNA polymorphisms in eastern hemlock: range-wide genogeographic analyses and implications for gene conservation. Canadian Journal of Forest Research, 41, 1047-1059.

Liu, X., \& Fu, Y.-X. (2015). Exploring population size changes using SNP frequency spectra. Nature Genetics, 47, 555-559.

Lynch, M. (1996). A quantitative-genetic perspective on conservation issues. In J. C. Avise \&J. L. Hamrick (Eds). Conservation genetics: case histories from nature (pp. 471-501). New York: Chapman and Hall.

Marsden, C.D., Ortega-Del Vecchyo, D., O’Brien, D.P., Taylor, J.F., Ramirez, O., Vilà, C., ... Lohmuller, K.E. (2016). Bottlenecks and selective sweeps during domestication have increased deleterious genetic variation in dogs. Proceedings of the National Academy of Sciences of USA, 133, 152-157.

Moyers, B.T., Morrell, P.L., \& McKay, J.K. (2018). Genetic costs of domestication and improvement. Journal of Heredity, 109, 103-116.

Mutke, S., Gordo, J., Khouja, M., \& Fady, B. (2013). Low genetic and high environmental diversity at adaptive traits in Pinus pinea from provenance tests in France and Spain. Options Méditerranées, 105, 73-79.

Mutke, S., Vendramin, G.G., Fady, B., Bagnoli, F., González-Martínez, S.C. 2019. Molecular and quantitative genetics of stone pine (Pinus pinea L.). In D. Nandwani (Ed.). Genetic diversity in horticultural plants (pp. 61-84). Switzerland: Springer Nature.

Nei, M., \& Li, W. H. (1979). Mathematical model for studying genetic variation in terms of restriction endonucleases. Proceedings of the National Academy of Sciences of USA, 76, 5269-5273.

Ohta, T. (1992). The nearly neutral theory of molecular evolution. Annual Review of Ecology and Systematics, 23, 263-286.

Peakall, R., \& Smouse, P.E. (2006). Genalex 6: genetic analysis in Excel. Population genetic software for teaching and research. Molecular Ecology Notes, 6, 288-295.

Pedersen, C.-E. T., Lohmueller, K.E., Grarup, N., Bjerregaard, P., Hansen, T., Siegismund, H.R., Moltke, I., \& Albrechtsen, A. (2017). The effect of an extreme and prolonged population bottleneck on patterns of deleterious variation: insights from the Greenlandic Inuit. Genetics, 205, 787-801. 
Perdiguero, P., Barbero M.C., Cervera, M.T., Collada, C., \& Soto, A. (2013). Molecular response to water stress in two contrasting Mediterranean pines (Pinus pinaster and Pinus pinea). Plant Physiology and Biochemistry, 67, 199-208.

Pérez-Jordà, G., Peña-Chocarro, L., García Fernández, M., \& Vera-Rodríguez, J.C. (2017). The beginnings of fruit tree cultivation in the Iberian Peninsula: plant remains from the city of Huelva (southern Spain). Vegetation History and Archaeobotany, 26, 527538.

Petit, R.J., \& Hampe A. (2006). Some evolutionary consequences of being a tree. Annual Review of Ecology, Evolution, and Systematics, 37, 187-214.

Pinzauti, F., Sebastiani, F., Budde, K.B., Fady, B., González-Martínez, S.C. \& Vendramin, G.G. (2012). Nuclear microsatellites for Pinus pinea (Pinaceae), a genetically depauperate tree, and their transferability to P. halepensis. American Journal of Botany, 99, e362-e365.

Plomion, C., Bartholomé, J., Lesur, I., Boury, C., Rodríguez-Quilón, I., Lagraulet, H., ... González-Martínez, S.C. (2016). High-density SNP assay development for genetic analysis in maritime pine (Pinus pinaster). Molecular Ecology Resources, 16, 574-587.

Popova, T., \& Hristova, H. (2018). Trees of eternity-Pinus pinea L. in daily life, rituals, religion and symbolism. Archaeobotanical evidence from the territory of Bulgaria. Journal of Archaeological Science: Reports, 19, 987-991.

Potter, K.M., Jetton, R.M., Dvorak, W.S., Hipkins, V.D., Rhea, R., \& Whittier, W.A. (2012). Widespread inbreeding and unexpected geographic patterns of genetic variation in eastern hemlock (Tsuga canadensis), an imperiled North American conifer. Conservation Genetics, 13, 475-498.

Prada, M.A., Gordo, J., de Miguel, J., Mutke, S., Catalán-Bachiller, G., Iglesias, S., \& Gil, L. (1997). Las regiones de procedencia de Pinus pinea L. en España. Madrid: Ministerio de Medio Ambiente, Organismo Autónomo Parques Nacionales.

Presgraves, D.C. (2005). Recombination enhances protein adaptation in Drosophila melanogaster. Current Biology, 15, 1651-1656.

Pritchard, J.K., Stephens, M., \& Donnelly, P. (2000) Inference of population structure using multilocus genotype data. Genetics, 155, 945-959.

Pritchard, J.K., Pickrell, J.K., \& Coop, G. (2010). The genetics of human adaptation: hard sweeps, soft sweeps, and polygenic adaptation. Current Biology, 20, R208-R215. 
892

893

894

895

896

897

898

899

900

901

902

903

904

905

906

907

908

909

910

911

912

913

914

915

916

917

918

919

920

921

922

923

Richardson, D.M. (ed.). (1998). Ecology and Biogeography of Pinus. Cambridge: Cambridge University Press.

Robinson, J.A, Ortega-Del-Vecchyo D., Fan, Z., Kim, B.Y., vonHoldt, B.M., Marsden, C.D., Lohmuller, K.E., \& Wayne, R.K. (2016). Genomic flatlining in the endangered island fox. Current Biology, 26, 1183-1189.

Ross-Davis, A., Ostry, M., \& Woeste, K.E. (2008). Genetic diversity of butternut (Juglans cinerea) and implications for conservation. Canadian Journal of Forest Research, 38, 899-907.

Rozas, J., Ferrer-Mata, A., Sánchez-DelBarrio, J.C., Guirao-Rico, S., Librado, P., RamosOnsins, S.E, \& Sánchez-Gracia, A. (2017). DnaSP v6: DNA sequence polymorphism analysis of large datasets. Molecular Biology and Evolution, 34, 3299-3302.

Rubiales, J.M., García-Álvarez, S., García-Amorena, I., Hernández, L., Morales-Molino, C., Moreno, E., \& Gómez-Manzaneque, F. (2011) Palaeobiogeographical perspectives on Pinus pinea L.: a controversial and enigmatic Mediterranean pine. $5^{\text {th }}$ Biennial Conference of the International Biogeography Society, Irakleion, Greece.

Sáez-Laguna, E., Guevara, M.-Á., Díaz, L.-M., Sánchez-Gómez, D., Collada, C., Aranda, I., \& Cervera, M.T. (2014). Epigenetic variability in the genetically uniform forest tree species Pinus pinea L. PLoS ONE, 9, e103145.

Saladin, B., Leslie, A.B., Wüest R.O., Litsios, G., Conti, E., Salamin, N. \& Zimmermann, N.E. (2017). Fossils matter: improved estimates of divergence times in Pinus reveal older diversification. BMC Evolutionary Biology, 17, 95.

Sánchez-Gómez, D., Velasco-Conde, T., Cano-Martín, F.J., Ángeles-Guevara, M.A., Cervera, M.T., \& Aranda, I. (2011). Inter-clonal variation in functional traits in response to drought for a genetically homogeneous Mediterranean conifer. Environmental and Experimental Botany, 70, 104-109.

Smith, N. G., \& Eyre-Walker, A. (2002). Adaptive protein evolution in Drosophila. Nature, 415, 1022-1024.

Tajima, F. (1983). 3. Evolutionary relationship of DNA sequences in finite populations. Genetics, 105, 437-460.

Vendramin, G.G., Fady, B., González-Martínez, S.C, Hu, F.-S., Scotti, I., Sebastiani, F., Soto, A., \& Petit, R.J. (2008). Genetically depauperate but widespread: the case of an emblematic Mediterranean pine. Evolution, 62, 680-688. 
Wallace, J.G., Rodgers-Melnick, E., \& Buckler, E.S. (2018). On the road to Breeding 4.0: Unraveling the Good, the Bad, and the Boring of crop quantitative genomics. Annual Review of Genetics, 52, 421-444.

Walter, R., \& Epperson, B.K. (2005). Geographic pattern of genetic diversity in Pinus resinosa: contact zone between descendants of glacial refugia. American Journal of Botany, 92, 92-100.

Watterson, G. A. (1975). On the number of segregating sites in genetical models without recombination. Theoretical Population Biology, 7, 256-276.

Wei, X., Zhao, L., Lascoux, M., \& Waxman, D. (2015). Population structure and the rate of evolution. Journal of Theoretical Biology, 365, 486-495.

Weissman, D.B. \& Barton, N.H. (2012). Limits to the rate of adaptive substitution in sexual populations. PLoS Genetics, 8, e1002740.

Welch, J.J., Eyre-Walker, A., \& Waxman, D. (2008). Divergence and polymorphism under the nearly neutral theory of molecular evolution. Journal of Molecular Evolution, 67,

$$
\text { 418-426. }
$$

Westbrook, J.W., Chhatre, V.E., Wu, L.-S., Chamala, S., Gomide-Neves, L. Muñoz, P., ... Echt, C.S. (2015). A consensus genetic map for Pinus taeda and Pinus elliottii and extent of linkage disequilibrium in two genotype-phenotype discovery populations of Pinus taeda. G3: Genes, Genomes, Genetics, 5, 1685-1694.

Wilcox, G.H. (1977). Exotic plants from Roman waterlogged sites in London. Journal of Archaeological Science, 4, 269-282.

Willyard, A., Cronn, R., \& Liston, A. (2009). Reticulate evolution and incomplete lineage sorting among the ponderosa pines. Molecular Phylogenetics and Evolution, 52, 498511.

Zhang, M., Zhou, L., Bawa, R., Suren, H., \& Holliday, J.A. (2016). Recombination rate variation, hitchhiking, and demographic history shape deleterious load in poplar. Molecular Biology and Evolution, 33, 2899-2910. 


\section{Legends to Figures}

FIGURE 1 Stone pine (P. pinea) distribution (green areas) and location of populations sampled for nuSSR (circles) and DNA sequence analyses (triangles). Circle color indicates the number of private alleles $\left(A_{\mathrm{PT}}\right)$ found for nuSSRs.

FIGURE 2 (A) Geographic distribution of mean genetic-cluster membership for stone pine (P. pinea) populations, as obtained from STRUCTURE analysis of nuSSR variation when assuming two genetic clusters $(K=2)$. (B) Individual bar-plot of genetic-cluster membership coefficients for the same analysis. (C) Distribution of $\Delta K$ values for the various numbers of genetic clusters $(K)$ assumed in STRUCTURE analyses. See Table S1 for population codes and additional details.

FIGURE 3 Genetic divergence and demographic history of stone pine (P. pinea). (A) Phylogenetic relationship and divergence times from maritime (P. pinaster) and loblolly (P. taeda) pines as determined from the Bayesian analyses of 50 nuclear gene-loci. Numbers and shaded rectangles over branches represent mean and 95\% credible intervals (CI) for divergence time estimates (in Ma), respectively. All nodes had posterior probabilities of 1.0. (B, C) Changes of population size over time for maritime (B) and stone (C) pines inferred with a stairway-plot derived from the site frequency spectrum (SFS) of 55,833 DNA-sequence sites. Dark and light lines represent the median and $95 \% \mathrm{CI}$, respectively. Estimates based on the assumption of a mutation rate of $1.64 \times$ $10^{-9}$ per site per year, and a generation time of 25 years. Blue areas denote glacial periods; those mentioned in the text are indicated on top of B. (D) Schematic representation of the best demographic scenario for stone pine according to DIYABC 
976 (based on the variation of 13 nuSSRs), and population parameters estimated from this

977 scenario (see Fig. S1 for all scenarios).

978

979 FIGURE 4 (A) Shared and non-shared (exclusive) mean number of SNPs found in 177

980 gene-loci in stone ( $P$. pinea) and maritime (P. pinaster) pines after their divergence from

981 loblolly pine (P. taeda). Exclusive SNPs are further subdivided in synonymous and non-

982 synonymous (replacements); non-synonymous variants are additionally separated in

983 putatively neutral and deleterious, according to functional effects inferred with PROVEAN

984 (Choi and Chan 2015). The mean number of fixed deleterious SNPs per species is also

985 indicated. (B) Proportion of (non-shared) non-synonymous substitutions fixed by

986 adaptive evolution $(\alpha)$ and relative rate of (non-shared) adaptive substitutions $(\omega \mathrm{a})$ per

987 species. (C) Distribution of fitness effects (DFE) of exclusive mutations in each taxa. 
TABLE 1 Mean DNA sequence diversity and divergence from loblolly pine (P. taeda)

991 estimated from 177 common gene-loci (representing 55,833 bp) in stone (P. pinea) and 992 maritime (P. pinaster) pines

993

\begin{tabular}{lll}
\hline Parameter* & Stone pine & Maritime pine \\
\hline$\theta_{\mathrm{w}}(S D)$ & $0.00015(0.00055)$ & $0.00231(0.00212)$ \\
$\pi(S D)$ & $0.00021(0.00125)$ & $0.00242(0.00243)$ \\
$\pi_{\mathrm{a}}(S D)$ & $0.00019(0.00126)$ & $0.00029(0.00407)$ \\
$\pi_{\mathrm{s}}(S D)$ & $0.00043(0.00353)$ & $0.00454(0.00474)$ \\
$\pi_{\mathrm{a}} / \pi_{\mathrm{s}}(S D)$ & $0.4487(0.5238)$ & $0.2561(0.4781)$ \\
$D_{\mathrm{xy}}(S D)$ & $0.0168(0.0115)$ & $0.0164(0.0117)$ \\
$K_{\mathrm{a}}(S D)$ & $0.0099(0.0114)$ & $0.0101(0.0115)$ \\
$K_{\mathrm{s}}(S D)$ & $0.0382(0.0289)$ & $0.0384(0.0317)$ \\
$K_{\mathrm{a}} / K_{\mathrm{s}}(S D)$ & $0.4598(1.0666)$ & $0.3315(0.5126)$
\end{tabular}

* Abbreviations: $S D$, standard deviation; $\theta \mathrm{w}$, average Watterson's nucleotide diversity

995 per site; $\pi$, average Tajima's nucleotide diversity per site; $\pi$ a, average $\pi$ for non-

996

synonymous sites; $\pi_{\mathrm{s}}$, average $\pi$ for synonymous sites; $\pi_{\mathrm{a}} / \pi_{\mathrm{s}}$, mean per gene ratio of

997 non-synonymous to synonymous nucleotide diversity; $D_{\mathrm{xy}}$, average pairwise divergence;

$998 K_{\mathrm{a}}$, average number of non-synonymous substitutions per non-synonymous site; $K_{\mathrm{s}}$, 999 average number of synonymous substitutions per synonymous site; $K_{\mathrm{a}} / K_{\mathrm{s}}$, mean per 1000 gene ratio of non-synonymous to synonymous substitutions. The last three estimates 1001 were determined using the Jukes-Cantor correction. 
TABLE 2 Genetic diversity (cpDNA, cpSSR, and nuSSR) in genetically depauperate but widespread plants, including stone pine. Clonal and self-fertilizing plants were excluded.

\begin{tabular}{lllllll}
\hline Species & Markers & $H_{0}$ & $H_{\mathrm{E}}$ & $H_{\mathrm{S}}$ & $H_{\mathrm{T}}$ & References \\
\hline Pinus resinosa & $9 \mathrm{cpSSR}$ & & & 0.543 & 0.618 & Echt et al. 1998 \\
& $10 \mathrm{cpSSR}$ & & 0.152 & & Walter and Epperson 2005 \\
& $5 \mathrm{nSSR}$ & 0.185 & 0.508 & & Boys et al. 2005 \\
\hline Pinus pinea & $3 \mathrm{cpSSR}$ & & & 0.019 & Vendramin et al. 2008 \\
& $9 \mathrm{nSSR}$ & 0.083 & 0.114 & & This study \\
\hline Juglans cinerea & $7 \mathrm{nSSR}$ & 0.760 & 0.750 & & 0.762 & Ross-Davis et al. 2008 \\
& $7 \mathrm{nSSR}$ & 0.659 & 0.691 & & Boraks and Broders 2016 \\
\hline Tsuga canadensis & $4 \mathrm{cpDNA}$ loci & & 0.727 & & Lemieux et al. 2011 \\
& $3 \mathrm{cpSSR}$ & & 0.672 & & Lemieux et al. 2011 \\
& $13 \mathrm{nSSR}$ & 0.566 & 0.526 & & Potter et al. 2012 \\
\hline
\end{tabular}




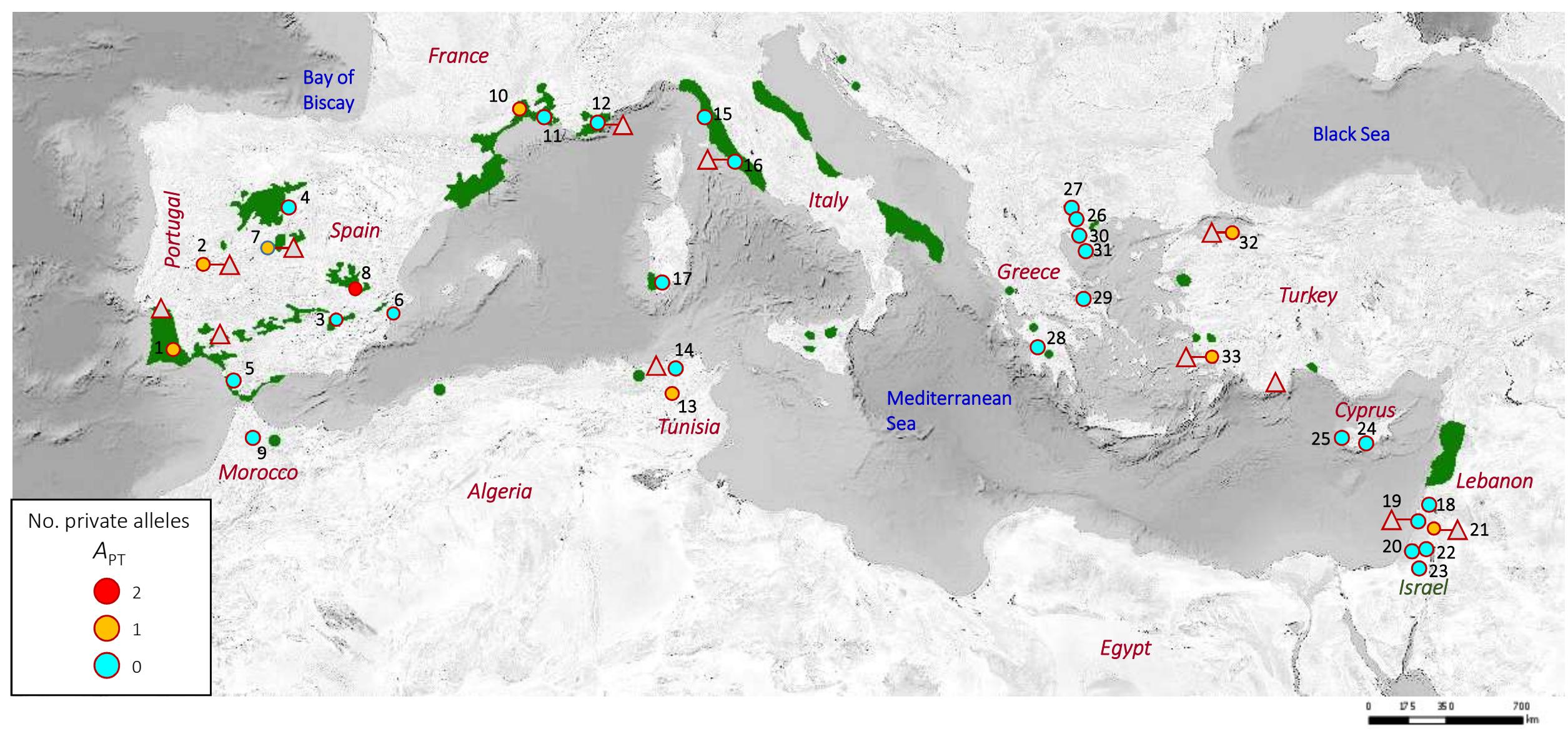




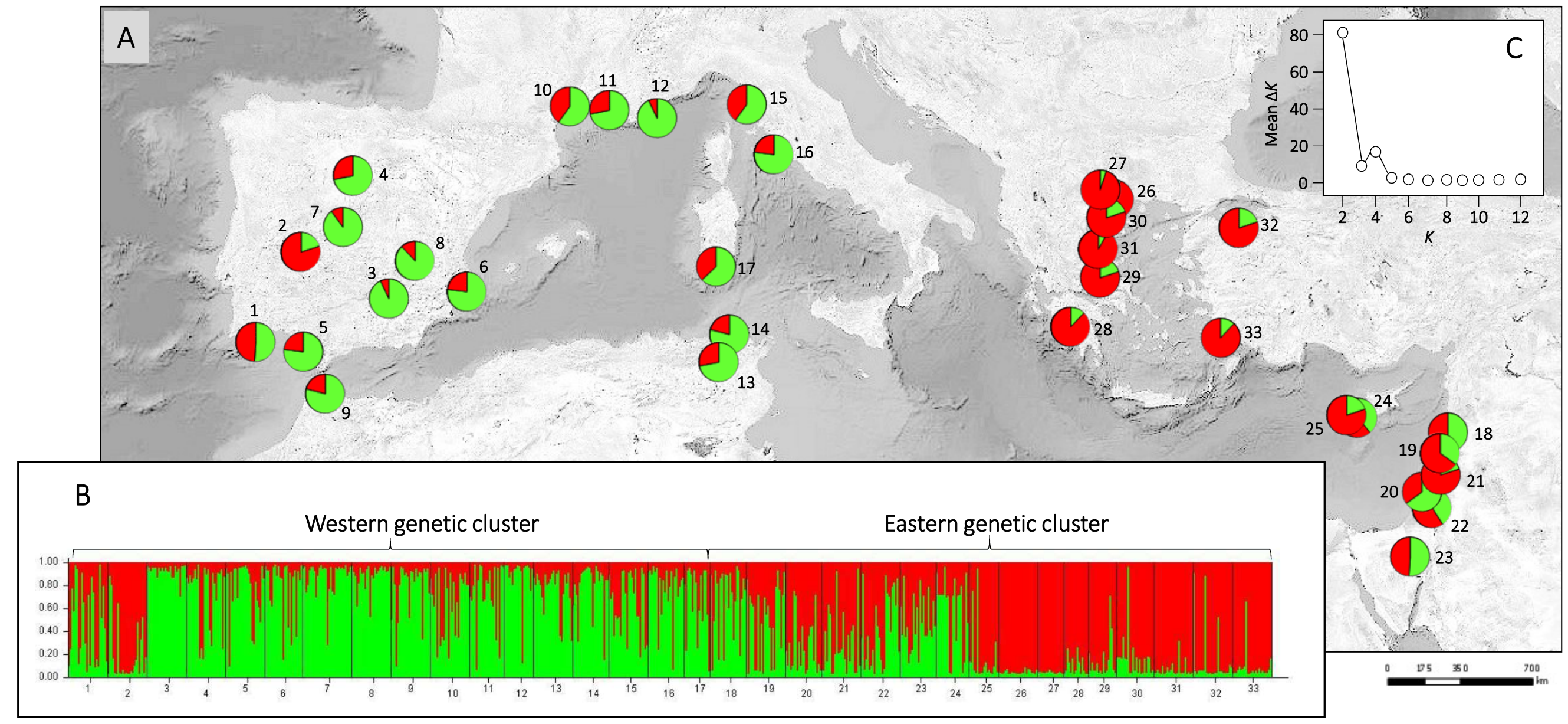




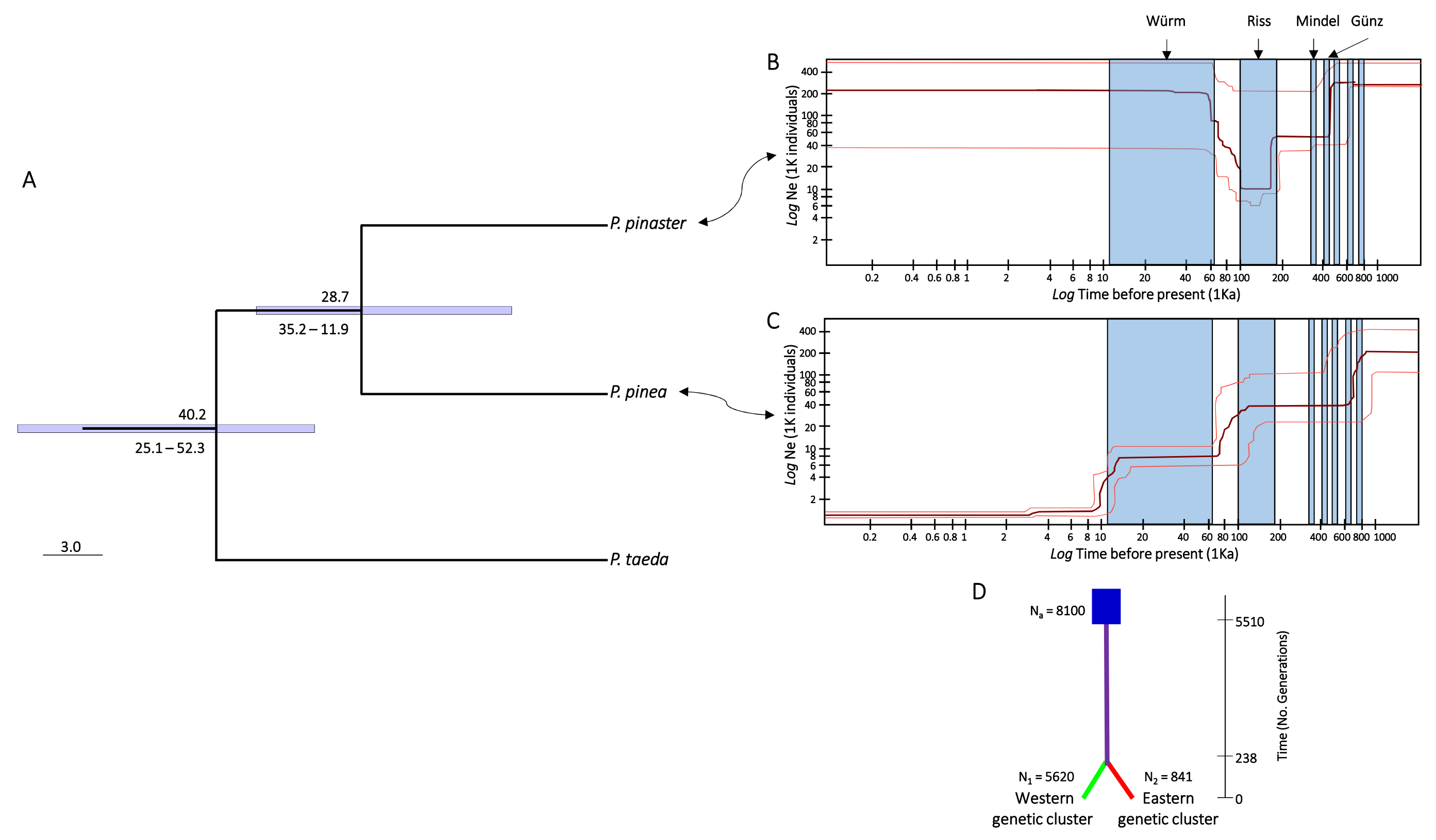



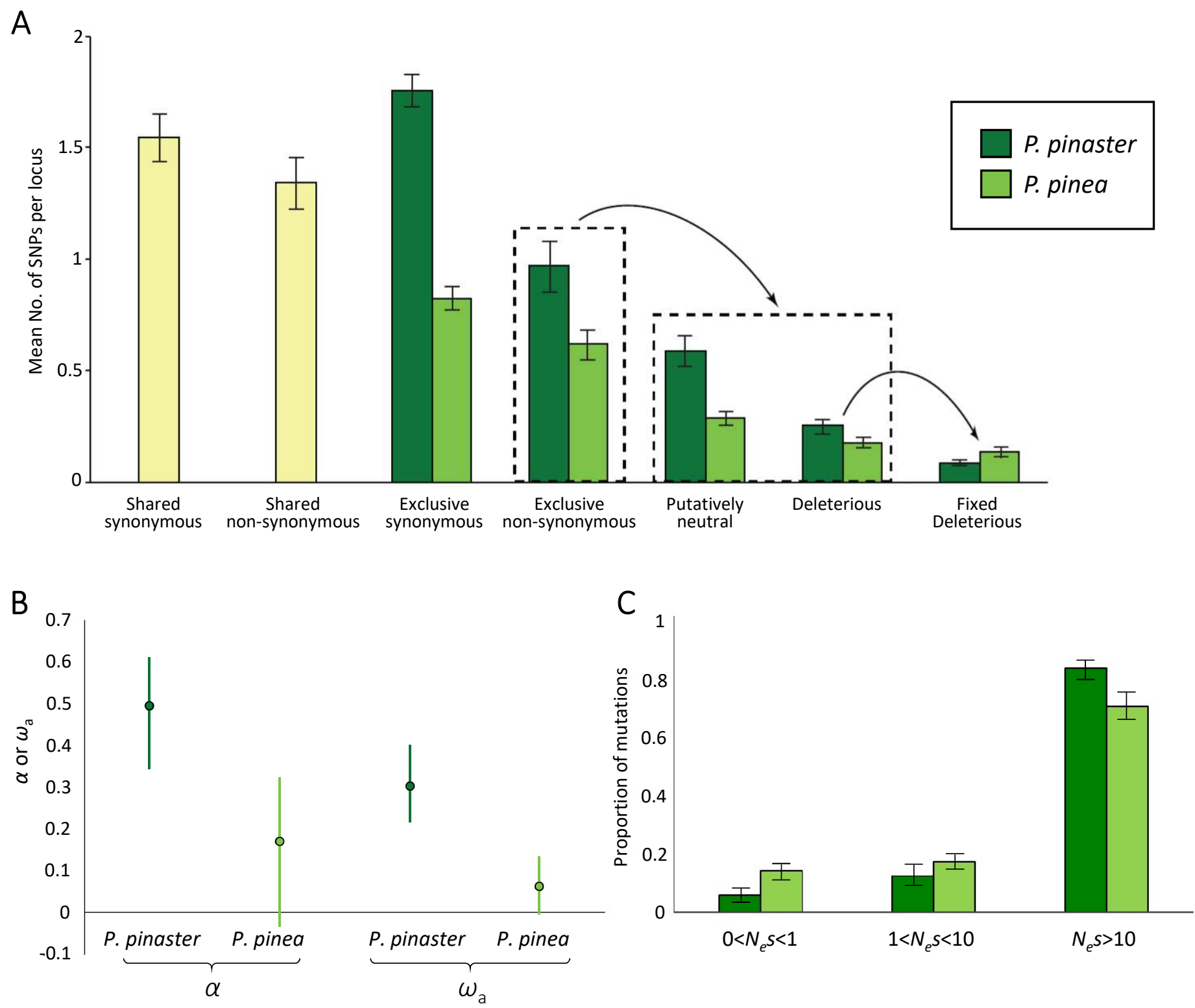